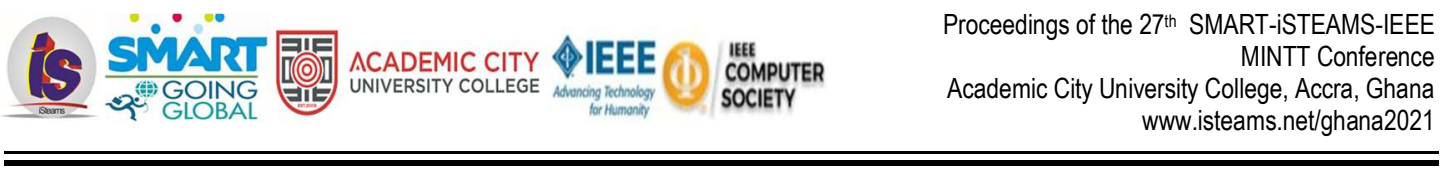

\title{
State and Future Prospects of Artificial Intelligence (AI) in Ghana
}

\author{
Amegadzie, J.K., Kanubala, D.D., Cobbina, K.A. \& Acquaye, C. \\ Faculty of Computational Sciences \& Informatics \\ Academic City University College \\ Accra, Ghana \\ E-mails: julius.amegadzie@acity.edu.gh; deborah.kanubala@acity.edu.gh \\ kwesi.cobbina@acity.edu.gh; christabel.acquaye@acity.edu.gh \\ Contacts: +233 502038558, +233 200745006, +233540777759, +233543548900
}

\begin{abstract}
This paper aims to give a broad scope of the current state of Al in Ghana. The paper highlights the existing institutions leveraging Al technologies, points out some current challenges with regards to Al adoption, and identifies some exciting prospects of Al given the current state of the country.
\end{abstract}

Keywords: Al, Machine Learning, Data Science, Technology.

Proceedings Reference Format

Amegadzie, J.K., Kanubala, D.D., Cobbina, K.A., Acquaye, C. \& Longe, O.B (2021): State and Future Prospects of Artificial Intelligence (Al) in Ghana. Proceedings of the 27th iSTEAMS Multidisciplinary Innovations \& Technology Transfer (MINTT) Conference. Academic City University College, Accra, Ghana. June, 2021. Pp 1-10 www.isteams.net/ghana2021. DOI - https://doi.org/ 10.22624/AIMS/iSTEAMS2021/N27P1

\section{INTRODUCTION}

The 4th Industrial revolution (4IR) has had an impact on every fibre of our lives. This impact has reverberated in almost every industry around the world, hence transforming systems of production, management, and governance (Schwab, 2016). This 4IR has been characterised by an ongoing digital revolution propelled by high-speed Internet accessibility, with its by-product as data, the new oil. It is estimated that the amount of data generated between the period of 2019 and 2020 is 59 zettabytes (Holst, 2021). Organizations are innovatively leveraging the prospects of this avalanche of data to harness its value for profit and growth. Additionally, the 4IR has given rise to emerging technologies (ET) such as Blockchain, the Internet of Things (IoT), Artificial Intelligence (AI), 5G, Robotics, Nanotechnology, etc.

Advanced countries have leveraged the power of the aforementioned ET to achieve various feats in many fields such as healthcare, e-commerce, manufacturing, education, automotive production, agriculture, military, governance, etc. Africa, as a continent, with its rising youth population (Sow, 2018), is gradually adopting the deployment of these ET as well. The upspring of technology-related start-ups as well as the presence of multinational companies in Africa, is a contributing factor to the growing adoption of ET in various industries. Ghana, located in the west of Africa, continues to attract multinational IT firms. Twitter's CEO announced in April 2021 that, it will establish its African headquarters in Ghana due to its support of online freedom, free speech, the Open Internet and a champion for democracy (Daniel, 2021). 


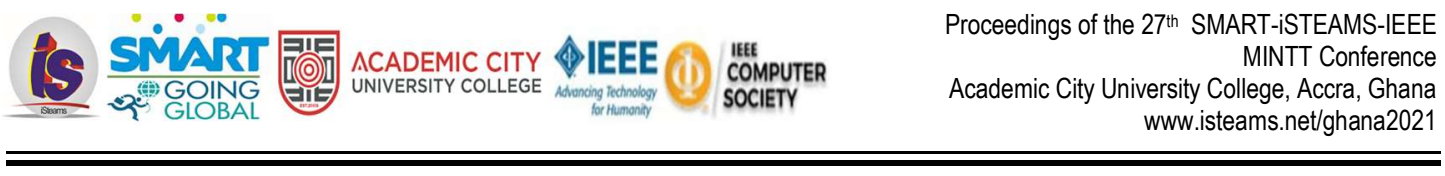

In April 2019, Google also opened its first Al lab in Ghana, headed by Mustapha Cisse, to spearhead African Al research (Adeoye, 2019).

In this paper, we investigate the state and future of one of these emerging technologies, Al, in Ghana. Although, there are quite a number of developments pertaining to Al in Ghana, no paper seems to have discussed them under one umbrella. This paper takes a unique approach of reviewing applications of $\mathrm{Al}$ in different domains in Ghana and also outlines its challenges and future propsects. This is to provide the research community what the Al space of Ghana currently looks like and opens up doors for potential applications and research directions. Al is defined as "a system's ability to correctly interpret external data, to learn from such data, and to use those learnings to achieve specific goals and tasks through flexible adaptation" (Kaplan and Haenlein, 2019).

\section{APPLICATIONS OF AI IN SELECTED SECTORS}

In this section, we would elaborate on the applications of Al in some selected sectors in Ghana.

\section{Education}

Al has so much power to transform and influence many industries including education, an important sector that helps to train and bridge the Al skill gap. Tencent, a Chinese technology business, has released a fresh analysis that confirms the shortage of Al skilled personnel. It suggests that there are around 300,000 "Al practitioners and researchers" globally, however, millions of positions are still vacant for persons with these skills (Winick, 2021). David Kellerman has already pioneered the use of Al in education by developing a question bot capable of answering and providing information to past lectures for students. He also developed a Power BI dashboard that compares students' examination answers and assists in the creation of customised study packs for future examinations based on prior performance (Ray, 2021).

As at the time of writing this paper, the authors did not come across any significant reseach on the application of $\mathrm{Al}$ in the area Education in Ghana. However, since instituions of learning and training are the wheels of talent development, we seek to highlight some institutions in Ghana that have already began training students in this area. Academic City University College, Accra, recently launched a 4-year bachelor degree program in Robotics Engineering. The program is designed to provide students with the necessary skill set and knowledge to thrive in future of workplace which will be largely driven by robots, artificial intelligence, etc., (Academic City University College , 2021) Additionally, the University's 3rd and 4th year Information Technology students take courses in Data Science and Artificial Intelligence respectively. Both courses seek to introduce students to the use of tools for acquiring data, cleaning data, exploring and making data-driven inferences and decisions.

Also, the African Masters of Machine Intelligence program funded by Google and Facebook is a novel oneyear intensive program which seeks to train African students with the state-of-the-art training in machine learning and its applications. The program which started in 2018 has already graduated almost 3 cohorts and has students working on very interesting and novel ideas to help solve the pressing challenges on the African continent. Moustapha Cisse, the Founder \& Director of AMMI indicated here that "if Al is to improve lives and reduce inequalities, we must build expertise beyond the present-day centers of innovation" (Cisse, 2018). 


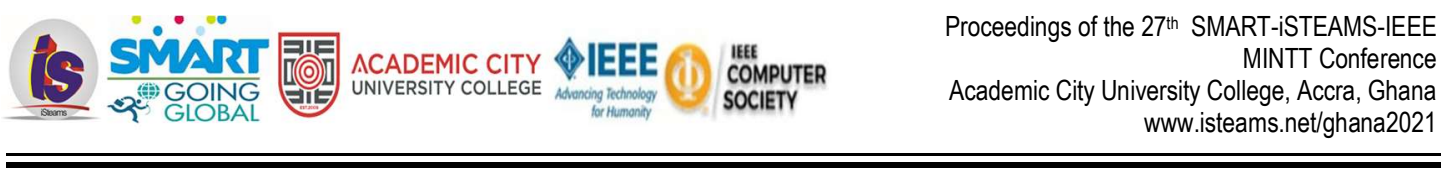

Aside University structured programs, 10Academy, Blossom Academy and Runmila Al Institute also have training programs that train talents across Africa with diverse academic backgrounds in data science, data analytic, and data engineering. 10Academy is non-profit and has already completed three(3) batches of training (10Academy, 2021a). AmaliTech also located in Takoradi, Sekondi has a two month long foundational training program after which trainees can take further specializations in different areas with data analytics inclusive (10Academy, 2021b).

\section{Agriculture}

Agriculture is one of the domains that stands to greatly benefit with the increase of Al technologies. Al has the ability to provide farmers with real-time observations from their farmlands. It could also be used to quickly identify crop/pest diseases, increase yields, thereby increasing food productivity. In Ghana, the KaraAgro Al \& Drones is a precision agriculture platform that aids farmers to reduce cost while improving their yields by early detection of anomalies through the use of high-resolution aerial imagery. Once the multispectral images are collected, KaraAgro Al makes use of analytic tools to help interpret the curated data and the necessary actions are taken. This process helps farmers to take actionable decisions based on the useful information obtained from aerial footage. Generally, KaraAgro Al is aiding farmers to easily detect crop diseases by simply taking a picture of crops. Tomato, Maize, Sweet Pepper, Potato, Grapes, Peach, Strawberry, Apple, and Cherry are among the crops for which KaraAgro Al has Artificial Intelligence systems (KaraAgro Al, 2021).

In addition, Sesi Technologies located in Kumasi, Ghana, recently launched Grain Moisture Meter which has the ability to quickly measure grain moisture content. The first GrainMate moisture which was named GM101 was released in 2018. However, an improved and updated model (GM102) was released in late 2020. The updated model is powered by two AA batteries which has the ability to last longer than the initially used batteries in GM-101 and 10 times cheaper. It also shortens the moisture reading time and offers an improved way of reading moisture with only the final reading displayed to the user (GrainMate, 2021).

\section{Security}

This is an area where some of the greatest breakthroughs can be made using Al but for a variety of reasons, Africa has not made great strides. From cross border security, efficient personnel deployment, vision systems to aid in tracking criminals to the analysis of crime data to aid security personnel in solving many unsolved cases we have on our continent. Currently, the most known applications of AI Systems in policing would be the use of the Crime Anticipation System, PreCobs, PredPol, and Hunchlab, etc. by the American and European Police departments (Hardyns and Rummens, 2018).

Also, a more advanced option is currently undergoing testing in Japans' Kanagawa Prefectural Police Department, which integrates various sets of biometrics and data analytics for crime prediction and prevention (Hung and Yen, 2020). On the African continent, very few nations are making policies to enable the regulated development of Al (Arthur et al., 2020). According to (Arthur et al., 2020) as of 2020, only Mauritius had put in place an Al Strategy though it is not clear what role it will play in the national security of the country. In Ghana, there exists no clear plan for the adoption of Al in security. Given the nature of the Ghanaian society, it is nearly impossible to adopt existing Al security systems deployed elsewhere without modifications to the Ghanaian society. 


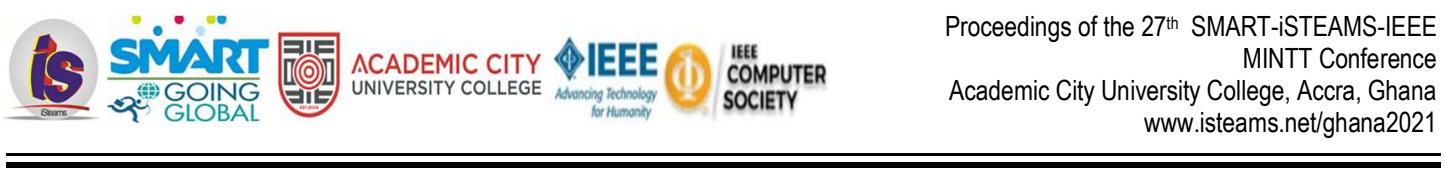

\section{Banking \& Finance}

One of the growing levers for digital payments in Africa has been the use of mobile money services. By the end of the year 2020, Sub-Saharan Africa was reported to have had 548 million registered mobile accounts, over which 150 million were active on a monthly basis (Andersson-Manjang and Naghavi, 2021). In Ghana, the Ghana Interbank Payment and Settlement Systems Limited (GhIPSS), a wholly owned subsidiary of the Bank of Ghana, has been incorporated and mandated to implement and manage interoperable payment system infrastructures for banks and non-bank financial institutions in Ghana. GhIPSS' strategic objective for the year 2020 was to drive adoption and usage of its real time payments services. At the end of 2020 a total of 77 million transactions were processed across all platforms, compared to 38 million transactions processed in 2019 , representing a $103 \%$ increase. The value of transactions processed in 2020 was GHC 254 billion, a 16\% increase compared to the GHC 219 billion processed in 2019 (GhIPSS, 2021). Interestingly, 43.9 million transactions were processed by the Mobile Money Interoperability (MMI) platform and its performance was driven by three (3) use cases namely: Transfers between wallets across Mobile Money Operators (MMOs); Transfers from mobile wallets to bank accounts and transfers from Mobile wallets to e-zwich Card wallets (GhIPSS, 2021).

One of the teething problems related to mobile money platforms is fraud. The Bank of Ghana reports that, in 2019 Ghana's banking industry reported a total number of 2,295 fraud cases (BOG, 2020). With relation to E-money fraud, a total amount of GHC 374, 392.92 was lost (BOG, 2020). Ghana's leading mobile subscriber platform, MTN Ghana, has indicated that it will acquire Artificial Intelligence (Al) technology to combat fraud-related activities with respect to its Mobile Money (MoMo) platform (Cudjoe, 2020).

In the field of core banking, the "Board of Directors of the African Development Bank has approved a grant of $\$ 1.024$ million for artificial intelligence enabled systems to process customer complaints on behalf of the national banks of Ghana and Rwanda and the Competition and Consumer Protection Commission of Zambia" (Terry, 2021). With regards to digital financial services, Nokwary Technologies and Ashesi University won a grant to develop a speech dataset in native Ghanaian languages (Twi and $\mathrm{Ga}$ ) (Sasu, 2019). This project is aimed at breaking the illiteracy barriers of native speakers of Twi and $\mathrm{Ga}$ and help them to easily access digital financial services. Currently Nokwary Technologies is developing a WhatsApp Al banking system which will enable illiterate users to access financial services by using voice notes (Owusu, 2020).

Also, BACE Group, a Ghanaian-based software company, won a grant to develop "a digital verification system that uses Artificial Intelligence and facial recognition to verify the identities of Africans remotely and in real time" (Salaudeen). It is an API that works by matching the live photo of a user to the image on their documents such as passports or ID card. This, when integrated with other systems will help curtail fraudulent activities since the real identities of users will be established.

\section{Health}

Over the years, great advances have been made with regards to Al (Dick, 2019) and its applications in the health sector as demonstrated by (Kaul et al., 2020). On the global scale, several technologies like Parthia with their cancer diagnostics model is assisting pathologists in making a much more accurate diagnosis of patient conditions (PathAl, 2019) and Enlitics' deep learning medical tools assist medical professionals by studying a patient's unstructured data to give a better insight into a patient's real-time needs(Enlitic, 2015). Both companies receiving worldwide recognition, can be considered as some of the leaders in the area of Health/Medical Al (Daley, 2020). 


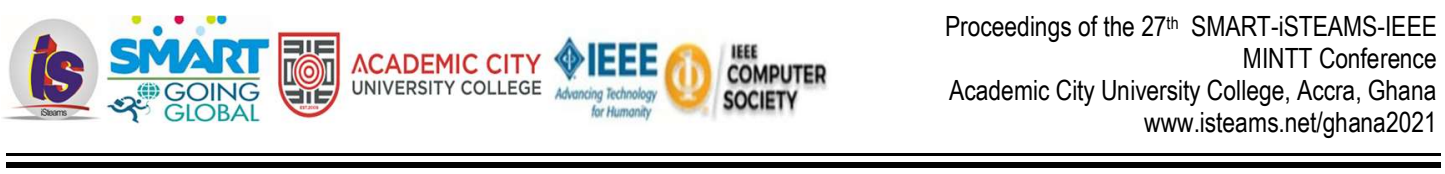

On the African continent, very few pilot projects have been seen in recent times. The use of Al by Ubenwa to aid in the diagnosis of birth asphyxia in low-resource settings (Onu et al., 2019) is one of such projects. Also, the works of Owoyemi et al. (2020) from Zambia in diabetics diagnosis among others are some of the very few efforts of experts across the continent working in this area. In Ghana, the most notable contribution to the application of Al in the healthcare sector is being spearheaded by MinoHealth AI Labs. It is important to note that the healthcare sector only recently saw the adoption of ICT and hence lacks the infrastructure and data to support varied applications of Al. MinoHealth's most recent research focuses on the diagnosis of malaria using machine learning and advanced data analytics in the identification of specific antibodies responsible for Malaria Immunity. They have also in the past worked on systems targeted towards the classification and identification of breast cancer cells (Akogo et al., 2018).

\section{Community/Outreach Groups}

There has been a growing interest in creating associations and organizations that seek to teach and create a niche of Al engineers and enthusiasts. This subsection will highlight a few of such groups' missions and impact on the Ghanaian Alfield. Ghana Natural Language Processing (Ghana NLP) is a group with almost 200 members. They started an open-source initiative focused on Ghanaian Languages and its applications to local issues. The members curated $25 \mathrm{k}+$ parallel English to Twi sentences and open-sourced their trained models on Hugging Face. The broad vision is to create a functioning google translate system for local languages like Twi, Ewe, Frafra, etc. (Ghana NLP, 2021).

In establishing a network of researchers who will focus on the appropriate development and applications of Al in Africa, the Responsible Al Network (RAIN) Africa was birthed. It is a collaboration between the Faculty of Electrical and Computer Engineering at Kwame Nkrumah University of Science and Technology (KNUST) in Ghana and the Institute for Ethics in Artificial Intelligence (IEAI) at the Technical University of Munich in Germany (RAIN Africa, 2021). RAIN Africa organizes timely workshops on Responsible Al, Al ethics, Future prospects and perspectives of Al in Africa, etc.

Also, in creating a space to support and promote women and gender minorities who are practicing, studying or interested in the fields of machine learning, Women in Machine Learning and Data Science (WiMLDS) was established in 2013. It is a non-profit organization set-up to create opportunities for its members to engage in technical and professional conversations. The organization currently has opened chapters in different cities in North America, Europe, Asia, South America, Oceania, and the Middle East, (WiMLDS, 2021). With 14 opened chapters in Africa, Ghana inclusive, the Ghana Accra WiMLDS chapter started late 2020 and currently has roughly 156 members. It organizes programs from time to time to equip their members with the relevant skills to advance their machine learning \& data science careers.

In addition, there are other organizations that are not solely limited to Ghana but Africa at large. Masakhane is one of such active groups and they seek to strengthen African NLP. As a grass-root organization, their goal is to improve and promote NLP study in African languages, by Africans, (Masakhane, 2021). Besides Matakana, Deep Learning Indaba seeks to strengthen the African Machine Learning community. Indaba which is a Zulu word meaning "a gathering or meeting" has the core value of bringing Africans together to share and learn. Indaba is working to achieve its mission to have Africans not as spectators but active shapers and owners of Al technologies through 3 of its principal programmes; the annual Deep Learning Indaba, the IndabaX, and the Kambule and Maathai awards (Indaba, 2021). 


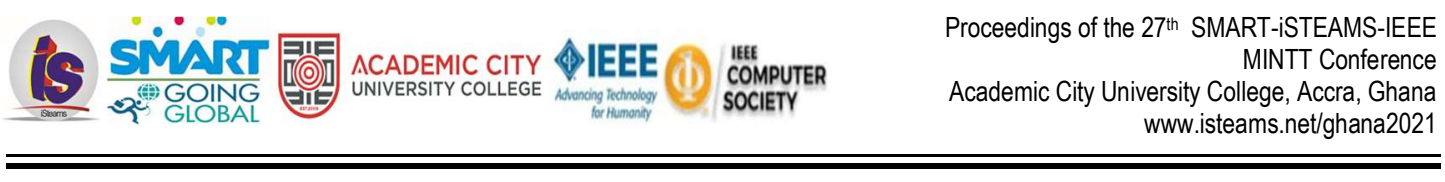

\section{CHALLENGES}

Artificial Intelligence has already shown great potential in transforming many industries today. However, this does not mean that there are no challenges that come along with it. Here, we discuss some challenges we envision with the practice of Al and also its future adoption in Ghanaian industries. The first major challenge envisaged is the lack of datasets. Al systems work well when presented with more training examples. Unfortunately, it is hard to build Al models such as machine translation systems, name entity recognition systems, question and answering systems, etc. due to the lack of well-curated text data. Even for datasets that are available, there are still challenges in accessing them. Additionally, in getting access to data, how do we ensure that data curated is devoid of any form of bias?

Bias data is translated into developed models which will extend to collecting additional bias data, hence, making decisions that negatively affect the lives of others. It would be an imperative action to document in detail, the steps involved in data collection to ensure that the data is able to correctly classify the phenomenon of interest.

Furthermore, developing good Al systems that would automate tasks, would mean having experts who can develop such systems. Unfortunately, there are currently few institutions in the country that have put in place courses that seek to train students in these areas. Aside from putting these courses in place, the country does not currently have advanced Al research labs with the tools needed to train students. Another major challenge is stable internet connectivity. Generally, internet is expensive and getting stable internet connectivity comes at an extra cost which makes it difficult for an average Ghanaian student to afford. All of these issues are challenges that will hinder the successful adoption of $\mathrm{Al}$ in the country.

\section{FUTURE PROSPECTS OF AI IN GHANA}

According to the global connectivity index ( $G C l, 2020)$, Ghana has seen a marginal growth of 6 connectivity points growing from $24 / 120$ to $30 / 120$ over the span of 5 years. We project this index to grow even further with the current policies being put in place by the government. With a growing population and a lot more connectivity on the horizon, some of the potential industries with the capabilities and use cases for the adoption of Al in the near future in the region are discussed. The government of Ghana has recently moved to digitalize all government agencies which in turn makes it easier to collect/generate data. The said digitalization will also facilitate the implementation of new technologies such as AI. Also the birth of CSquared which led the charge of fiber optic connectivity along with MainOne has enabled the capacity of major cities in the country to connect to the internet see an exponential growth since 2015 (CSquared, 2021) (Finley, 2015).

Much like government agencies, a large number of hospitals have moved to digitalize their healthcare processes. With this digitalization comes a varied number of Al implementations that can be made. The work done by Akogo et al. (2018) is one of such examples which would aid doctors in diagnosing breast cancer. Another great example could be a Ghanaian built Reinforced Deep Learning analysis tool to study and understand patients records to give a holistic overview of a patients' current conditions and possibly make calculated predictions of future conditions that need to be monitored. The government of Ghana in the period between 2019 and 2020 has under the alpha project worked on the procurement and installation of 10,000 CCTV cameras for use across the nation (Lartey, 2020). 
When completed the possibilities would be endless. The massive data that will be collected of the faces of the people in the country together with driving data, paired with the national identification cards which have all been digitalized would aid in the faster tracking and apprehension of criminals. The data on driving could also be used to train self- driving cars capable of driving on some of our deplorable roads. The advent of mobile banking on the continent as a whole has presented some novel challenges unique to this technology. The work done by Isaac et al. (2019) found that one of the factors responsible for mobile money fraud was the lack of systems designed to track and detect events of fraud in the mobile money market. The ability of machine learning algorithms to study the usage patterns could be used to identify fraudulentactivities.

\section{CONCLUSION}

In summary, this paper discussed the current state of $\mathrm{Al}$ in Ghana, its challenges, and elaborated on a limited number of its future prospects. The work of Travaly and Muvunyi (2020) also highlights some significant areas relevant to this discourse. Noted among them is genomic precision in livestock production models.

The rapid change of technology requires that humanity embraces "agile governance" where governments have to work closely with regulatory agencies, businesses and civil societies and adapt rapidly for the good of their citizens (Schwab, 2016). Government policies need to be structured to support Al innovation and to create a fostering environment for Al businesses. A comprehensive policy of $\mathrm{Al}$ and its adoption in the Ghanaian community needs to be drafted by a cohort of experts assembled from academia, industry and governmental agencies. This policy must include a clear plan of how we will achieve Al assimilation and laws governing Al usage as well as bias in Al. Educational institutions should consciously integrate the teaching of $\mathrm{Al}$ and its related fields in their curricula. This will help increase the Al skilled personnel in the nation and further act as catalysts for other industries to booster overall development. As private organisations have over the years led the charge for innovation, Ghana and for that matter Africa, is a unique test case for the expansive use of $\mathrm{Al}$ as well other emerging technologies. 


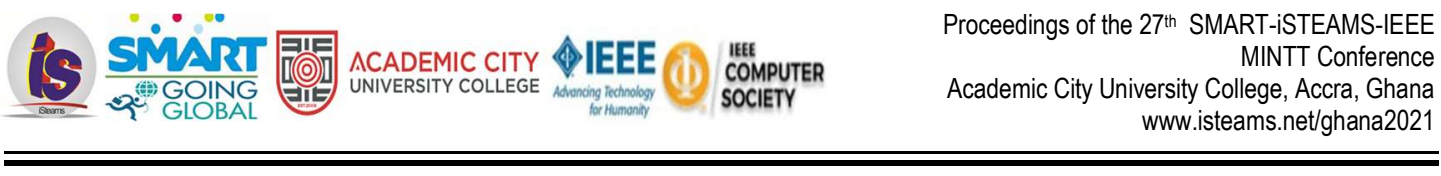

\section{BIBLIOGRAPHY/REFERENCES}

1. 10Academy. Training Highly Talented Young Africans For Careers With Outsized Impact, 2021a. URL https://www.10academy.org/about.

2. 10Academy. AmaliTech Program, 2021b. URL https://amalitech.org/our-programme/\#.

3. Academic City University College . ACity Outdoors Robotics and Biomedical Engineering Bachelor's Degree Programs, 2021. URL https://medium.com/acity-journal/ acity-outdoors-robotics-and-biomedical-engineering-bachelors-degree-programscd1be7ee7c9e.

4. Adeoye. Google has opened its first Africa Artificial Intelligence lab in Ghana - CNN, Apr. 2019. URL https://edition.cnn.com/2019/04/14/africa/google-ai-center-accra-intl/ index.html.

5. D. Akogo, V. Appiah, and X.-L. Palmer. CellLineNet: End-to-End Learning and Transfer Learning For Multiclass Epithelial Breast cell Line Classification via a Convolutional Neural Network, 2018.

6. G. Arthur, K.-M. Erika, R. Nagla, R. Isaac, and d. B. Jeremy. Artificial intelligence (ai) deployments in africa: Benefits, challenges and policy dimensions. The African Journal of Information and Communication, 26:1-28, 2020. doi: https://dx.doi.org/10.23962/10539/30361.

7. BOG. The 2019 Banking Industry Fraud Report - Bank of Ghana, Dec. 2020. URL

8. https://www.bog.gov.gh/news/the-2019-banking-industry-fraud-report/.

9. M. Cisse. Looktoafricato advance artificial intelligence. Nature,2018. doi: d41586-018-07104-7. CSquared. About us, 2021. URL https://csquared.com/about-us/.

10. K. Cudjoe. MTN to deploy Al, others to fight MoMo fraud, Oct. 2020. URL https://thebftonline. com/13/10/2020/mtn-to-deploy-ai-others-to-fight-momo-fraud-2/.

11. S. Daley. 32 examples of ai in healthcare that will make you feel better about the future, 2020. URL

12. https://builtin.com/artificial-intelligence/artificial-intelligencehealthcare.

13. L. Daniel. Twitter chooses Ghana as its African headquarters, says its due to country's support of free speech, Apr. 2021. URL https://www.businessinsider.co.za/ twitter-opensafrica-headquarters-in-ghana-2021-4.

14. S. Dick. Artificial intelligence. Harvard Data Science Review, 1(1), 7 2019. doi: 10.1162/99608f92.92fe150c. URL https://hdsr.mitpress.mit.edu/pub/Oaytgrau. https://hdsr.mitpress.mit.edu/pub/0aytgrau.

15. Enlitic. Deep learning in diagnostic healthcare: The future? 2015. URL https://www.idgconnect. com/article/3579184/deep-learning-in-diagnostic-healthcarethe-future.html.

16. E. Winick. It's Recruiting Season for Al's Top Talent, and Things Are Get- ting a Little Zany, 2021. URL https://www.technologyreview.com/2017/12/06/147263/ itsrecruiting-season-for-ais-top-talent-and-things-are-getting-a-little-zany/.

17. K. Finley. Google project link, 2015. URL https://www.wired.com/2015/10/ google-projectlink/.

18. GCl, 2020. URL https://www.huawei.com/minisite/gci/en/country-profilegh.html\#gh2015. Ghana NLP. Ghana Natural Language Processing (NLP), 2021. URL https://ghananlp.org/.

19. GhIPSS. 2021 GhIPSS Annual Media Engagement, 2021. URL https://ghipss.net/publications. 


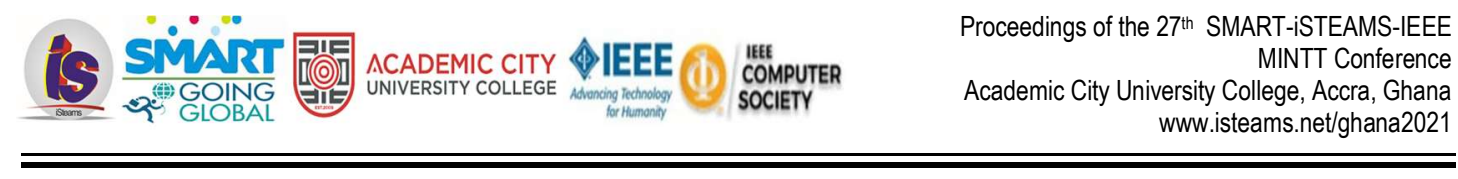

20. GrainMate. Introducing The New GrainMate GM-102 Grain Moisture Meter, 2021. URL https:// sesitechnologies.com/introducing-the-new-grainmate-gm-102-grain-moisturemeter/.

21. W. Hardyns and A. Rummens. Predictive policing as a new tool for law enforcement? recent developments and challenges. European Journal on Criminal Policy and Research, 24, 092018. doi: 10.1007/s10610-017-9361-2.

22. Holst. Total data volume worldwide 2010-2024, May 2021. URL https://www.statista.com/ statistics/871513/worldwide-data-created/.

23. T.-W. Hung and C.-P. Yen. On the person-based predictive policing of ai. Ethics and Information Technology, 06 2020. doi: 10.1007/s10676-020-09539-x.

24. Indaba. Deep Learning Indaba, 2021. URL https://deeplearningindaba.com/about/ ourmission/.

25. A.-F. Isaac, A. Charles, A.-F. Agnes, and D.-O. Yvonne. Control of fraud on mobile money services in Ghana: an exploratory study. Journal of Money Laundering Control, 22:300-317, 2019. doi: https://doi.org/10.1108/JMLC-03-2018-0023.

26. Kaplan and M. Haenlein. Siri, Siri, in my hand: Who's the fairest in the land? On the interpretations, illustrations, and implications of artificial intelligence. Business Horizons, 62(1):15-25, Jan. 2019. ISSN 0007-6813. doi: 10.1016/j.bushor.2018.08.004. URL https://www.sciencedirect.com/ science/article/pii/S0007681318301393.

27. KaraAgro Al. KaraAgro AI \& Drones, 2021. URL https://www.karaagro.com/.

28. V. Kaul, S. Enslin, and S. Gross. History of artificial intelligence in medicine. Gastrointestinal Endoscopy Journal, 92:807-812, 06 2020. doi: https://doi.org/10.1016/j.gie.2020.06.040. URL https://www.giejournal.org/article/S0016-5107(20)34466-7/pdf.

29. N. L. Lartey. Ipha project: Gov't to install 10,000 cctvs nationwide to fight crime, 2020. URL https://citinewsroom.com/2020/01/ alpha-project-govt-to-install-10000-cctvs-nationwide-to-fight-crime/.

30. Masakhane. Masakhane (A grassroots NLP community for Africa, by Africans), 2021. URL

31. https://www.masakhane.io/.

32. C. C. Onu, J. Lebensold, W. L. Hamilton, and D. Precup. Neural Transfer Learning for Cry-Based Diagnosis of Perinatal Asphyxia. In Proc. Interspeech 2019, pages 3053-3057, 2019. doi: 10.21437/Interspeech.2019-2340. URL http://dx.doi.org/10.21437/Interspeech.20192340.

33. A. Owoyemi, J. Owoyemi, A. Osiyemi, and A. Boyd. Artificial intelligence for healthcare in Africa.

34. Frontiers in Digital Health, 2020. doi: https://doi.org/10.3389/fdgth.2020.00006.

35. D. Owusu. Understanding Al's Role in WhatsApp Banking - Al and NLP in Ghana and Africa, May 2020. URL https://nokwary.com/blog/2020/05/21/ understanding-ais-role-in-whatsapp-banking/.

36. PathAl. PathAl and Gilead Show Al-Powered Pathology Research Models Accurately Interpret Liver Histology in Patients with NASH at AASLD 2019, 2019. URL https://www.pathai.com/news/ pathai-gilead-nash-aasld-liver-2019.

37. RAIN Africa. Responsible AI Network - Africa, 2021. URL https://rainafrica.org/.

38. S. Ray. High tech for higher ed: An australian engineering professor revamps student learning with teams. Website, 2021. https://news.microsoft.com/features/

39. high-tech-for-higher-ed-an-australian-engineering-professor-revampsstudent-learning-with-teams/. 
40. A. Salaudeen. A26-year-old is first woman to win the Royal Academy of Engineering's Africa Prize. URL https://www.cnn.com/2020/09/07/africa/africa-engineering-prize-int// index.html.

41. D. Sasu. Developing a functional Natural Language Processing system for the Twi language with limited data. Thesis, Apr. 2019. URL https://air.ashesi.edu.gh/handle/20.500.11988/507. Accepted: 2020-03-31T13:14:31Z.

42. K. Schwab. The Fourth Industrial Revolution: what it means and how to respond, Jan. $2016 . \quad$ URL

https://www.weforum.org/agenda/2016/01/ the-fourth-industrial-revolution-what-itmeans-and-how-to-respond/.

43. S. K. Andersson-Manjang and N. Naghavi . State of the Industry Report on Mobile Money, 2021.

44. M. Sow. Figures of the week: Africa's growing youth population and human capital investments, Sept. 2018. URL https://www.brookings.edu/blog/africa-in-focus/2018/09/20/ figures-of-the-week-africas-growing-youth-population-and-human-capital-investments/.

45. O. D. Terry. African Development Bank provides $\$ 1$ million for Al-based national customer management systems in Ghana, Rwanda and Zambia, Mar. 2021. URL https://www.afdb.org/en/news-and-events/press-releases/

46. african-development-bank-provides-1-million-ai-based-national-customermanagement-systems-ghana-rwanda-

47. Publisher: African Development Bank Group.

48. Y. Travaly and K. Muvunyi. The future is intelligent: Harnessing the potential of artificial intelligence in africa, 2020. URL https://www.brookings.edu/blog/africa-infocus/2020/01/13/

49. the-future-is-intelligent-harnessing-the-potential-of-artificialintelligence-in-africa/.

50. WiMLDS. Women in Machine Learning and Data Science, 2021. URL http://wimlds.org/ chapters/. 